\title{
Genome-wide association for grain yield under rainfed conditions in historical wheat cultivars from Pakistan
}

\section{OPEN ACCESS}

Edited by:

Ann E. Stapleton,

University of North Carolina

Wilmington, USA

Reviewed by:

Shichen Wang,

Kansas State University, USA

Jeff $H$. Chang,

Oregon State University, USA

*Correspondence:

Umar M. Quraishi,

Department of Plant Sciences, Faculty of Biological Sciences, Quaid-i-Azam University, Islamabad 45320, Pakistan

umasood@qau.edu.pk

Specialty section:

This article was submitted to

Plant Genetics and Genomics,

a section of the journal

Frontiers in Plant Science

Received: 13 April 2015

Accepted: 31 August 2015

Published: 22 September 2015

Citation:

Ain Q, Rasheed A, Anwar A, Mahmood T, Imtiaz M, Mahmood T, Xia X, He Z and Quraishi UM (2015) Genome-wide association for grain yield under rainfed conditions in historical wheat cultivars from

Pakistan. Front. Plant Sci. 6:743. doi: $10.3389 /$ fpls.2015.00743

\begin{abstract}
Qurat-ul Ain ${ }^{1}$, Awais Rasheed ${ }^{2,3}$, Alia Anwar', Tariq Mahmood ${ }^{4}$, Muhammad Imtiaz ${ }^{5}$, Tariq Mahmood ${ }^{1}$, Xianchun Xia ${ }^{2}$, Zhonghu $\mathrm{He}^{2,3}$ and Umar M. Quraishi ${ }^{1 *}$

${ }^{1}$ Molecular Plant Breeding, Department of Plant Sciences, Quaid-i-Azam University, Islamabad, Pakistan, ${ }^{2}$ National Wheat Improvement Center, Institute of Crop Science, Chinese Academy of Agricultural Sciences, Beijing, China, ${ }^{3}$ International Maize and Wheat Improvement Center (CIMMYT), C/O Chinese Academy of Agricultural Sciences, Beijing, China, ${ }^{4}$ Higher Education Commission, Research and Development, Islamabad, Pakistan, ${ }^{5}$ International Maize and Wheat Improvement Center (CIMMYT), C/O National Agriculture Research Center, Islamabad, Pakistan
\end{abstract}

Genome-wide association studies (GWAS) were undertaken to identify SNP markers associated with yield and yield-related traits in 123 Pakistani historical wheat cultivars evaluated during 2011-2014 seasons under rainfed field conditions. The population was genotyped by using high-density Illumina iSelect 90K single nucleotide polymorphism (SNP) assay, and finally 14,960 high quality SNPs were used in GWAS. Population structure examined using 1000 unlinked markers identified seven subpopulations $(K=7)$ that were representative of different breeding programs in Pakistan, in addition to local landraces. Forty four stable marker-trait associations (MTAs) with $-\log p>4$ were identified for nine yield-related traits. Nine multi-trait MTAs were found on chromosomes $1 \mathrm{AL}, 1 \mathrm{BS}, 2 \mathrm{AL}, 2 \mathrm{BS}, 2 \mathrm{BL}, 4 \mathrm{BL}, 5 \mathrm{BL}, 6 \mathrm{AL}$, and $6 \mathrm{BL}$, and those on $5 \mathrm{BL}$ and $6 \mathrm{AL}$ were stable across two seasons. Gene annotation and syntey identified that 14 trait-associated SNPs were linked to genes having significant importance in plant development. Favorable alleles for days to heading $(\mathrm{DH})$, plant height $(\mathrm{PH})$, thousand grain weight (TGW), and grain yield (GY) showed minor additive effects and their frequencies were slightly higher in cultivars released after 2000. However, no selection pressure on any favorable allele was identified. These genomic regions identified have historically contributed to achieve yield gains from 2.63 million tons in 1947 to 25.7 million tons in 2015 . Future breeding strategies can be devised to initiate marker assisted breeding to accumulate these favorable alleles of SNPs associated with yield-related traits to increase grain yield. Additionally, in silico identification of 454-contigs corresponding to MTAs will facilitate fine mapping and subsequent cloning of candidate genes and functional marker development.

Keywords: spring bread wheat, genome-wide association studies (GWAS), marker trait association, single nucleotide polymorphism (SNP), 90K SNP assay, gene annotation, grain yield 


\section{Introduction}

Historically, breeding has contributed to radical increases in cereal production, particularly by the use of dwarf genes and exploitation of heterosis. However, grain production must increase by $70 \%$ from present levels to meet projected world food requirements by 2050 (Ray et al., 2013). Wheat as one of the most important cereal crops, will become increasingly important for food security under climate change conditions, in addition to the shortage of water and other resources. Wheat varieties with high yield and an appropriate end-use quality is the primary objective of all breeding programs around the world. Grain yield (GY) is governed by numerous genes that interact with each other and with the environment (Quarrie et al., 2006). Total Grain yield is a complex trait contributed by multiple yield components, and each component is a quantitative trait controlled or affected by several genes (Zhang et al., 2010b). Thus, there must be detailed genetic dissection of the yield trait in order to manipulate each gene to greatest advantage.

Although breeding progress for improved GY has been achieved for irrigated environments (Langridge and Reynolds, 2015), much less gain has occurred in rainfed environment (Ray et al., 2012). The problem is more severe in drought-prone environments, and the yield gaps between high production areas and dryland agriculture are very large. Strategies to reduce this gap include the genetic improvements under drought conditions by identifying sources of traits associated with drought tolerance and subsequent introgression of genes underlying the target traits to locally adapted cultivars. The challenge for implementing such strategies in breeding programs is identification of the most suitable target traits in a time-efficient and cost-effective way for different drought scenarios (Richards et al., 2014). Recent advancements in high throughput genotyping and phenotyping have improved understanding of the physiological and molecular basis underlying complex traits including drought tolerance (Salekdeh et al., 2009; Langridge and Reynolds, 2015).

Absence of a completely sequenced reference genome in wheat has limited gene discovery in bread wheat in last decade and recent advancement in field of functional genomics have rendered a new push to breeders to achieve their goals (Pingault et al., 2015). But at present, the best alternate choice for wheat breeder is the use of high-density single nucleotide polymorphism (SNP) assays to define genomic regions associated with quantitative traits either in bi-parental mapping experiments or in genome-wide association studies (GWAS) (Bordes et al., 2014; Edae et al., 2014; Zanke et al., 2014b). Several studies have identified chromosomal regions involved in yield performance, either by QTL analysis using linkage maps (Zhang et al., 2010b; Bennett et al., 2012; Liu et al., 2012; Mir et al., 2012) or by association mapping based on linkage disequilibrium (LD) (Bordes et al., 2013, 2014; Lopes et al., 2014; Zanke et al., 2014a,b). However, much more work is needed due to the bottleneck arising from the lack of inconsistency among studies, and use of low density marker platforms in gene mapping studies. Recently, several medium to high density SNP assays have been developed based on their distribution across the genome, minor allele frequency (MAF) and inter-variant LD using various technological principles (Akhunov et al., 2009; Saintenac et al., 2011; Poland et al., 2012; Wang et al., 2014). GWAS in wheat is challenging due to the large genome, incomplete genome sequence, and polyploidy, those make it difficult to assign the markers to the highly similar homeologous chromosomes (Sukumaran and Yu, 2014). Therefore, a combined meta-genomic approach using comparative analyses of cereals and GWAS may provide an opportunity to accelerate identification of genes controlling quantitative traits in wheat (Quraishi et al., 2011).

Bread wheat, a staple food crop in Pakistan, is grown on $7.8 \mathrm{~m} \mathrm{ha}$, including $2.2 \mathrm{~m}$ ha under rainfed condition. CIMMYT germplasm with 1BL.1RS translocation and their derivatives has been used both under irrigated and rainfed environments. However, they even provided better adaptability in rainfed environments, and contributed to reduced yield penalties associated with water stress (Tahir et al., 2014). Thus, much more efforts are needed to dissect genetic mechanisms underpinning adaptation to drought conditions and to devise marker-based breeding strategies that involve marker-assisted selection or genome-wide selection to obtain the required genetic gains. The present study was designed to identify the stable genomic regions associated with adaptation to rainfed conditions in historical wheat cultivars of Pakistan. We used the $90 \mathrm{~K}$ SNP assay for GWAS for yield related traits, and SNP-flanking sequences were then used to predict the functions of MTAs involved in high yielding Pakistani cultivars.

\section{Materials and Methods}

\section{Plant Materials and Phenotyping}

The plant material was a collection of 123 Pakistan spring wheat cultivars adapted to irrigated, semi-arid, and arid climatic zones (Supplementary Table 1). The collection comprised four groups based on genetic background and time of release; 10 cultivars pre-dated the Green Revolution i.e., cultivated before 1965, 23 were Green Revolution era released during 1960-1979, 45 post Green Revolution released during 1980-2000, and 45 were modern cultivars released during 2000-2014. The seeds were obtained from the Plant Genetic Resources Institute, National Agricultural Research Centre, Islamabad, Pakistan. Field trials were performed at the National Agriculture Research Centre, Islamabad in 2011-12, 2012-13, and 2013-14 seasons using an alpha lattice design with three replications of $1 \times 2 \mathrm{~m}^{2}$ plots. Soil samples were collected from four random sites of each field/year and soil parameters were recorded before planting. The soil had mean EC values of $0.30 \mathrm{dS} \mathrm{m}^{-1}, 7.8 \mathrm{pH}, 0.70 \%$ organic matter, $4.5 \mathrm{mg} \mathrm{kg}^{-1}$ available-P, $130 \mathrm{mg} \mathrm{kg}^{-1}$ available- $\mathrm{K}$ and textural class loam 13.

Nine phenotypic traits were evaluated, including days to heading $(\mathrm{DH})$, days to maturity $(\mathrm{DM})$, plant height $(\mathrm{PH})$, spike number (SN) (spike number $\mathrm{m}^{-2}$ ), grain numbers per spike (GN), thousand grain weight (TGW), grain yield (GY), biological yield (BY), and harvest index (HI). DH were recorded on $50 \%$ spike emergence, and DM were recorded when $50 \%$ of spikes showed total loss of green color. PH was measured after physiological maturity by measuring the distance between the 
stem base and the top of the spike excluding awns. SN was scored in $1 \mathrm{~m}$ sample and then transformed to spike number per $\mathrm{m}^{2}(\mathrm{SN})$. GN was calculated from the mean of 30 randomly selected spikes in each plot. After harvest, TGW was measured by weighing duplicates of 500 kernels from each plot. Grain yield (GY) was determined as the weight of grain harvested per unit area $\left(\mathrm{g} \mathrm{m}^{-2}\right)$. BY was estimated as the weight of the above ground biomass for whole plots at $72 \mathrm{~h}$ after harvest, and then HI was calculated.

\section{Genotyping}

Five seeds of each cultivar were planted in $5 \mathrm{~cm}$ diameter pots. Fresh leaf samples for DNA extraction were collected from 25day old seedlings. DNA extraction was carried out according to the CIMMYT Molecular Genetics Manual (Dreisigacker et al., 2012). Subsequently, DNA samples (50-100 ng/ $\mu$ l per sample) in 96 -well plate formats were sent to CapitalBio ${ }^{\circledR}$ genotyping facility in Beijing for genotyping with high-density illumina 90K infinium SNP array (Wang et al., 2014). PowerMarker v. 3.0 was used to estimate genetic similarities between wheat lines with a Dice coefficient based on the proportion of shared alleles (Liu et al., 2005). Genetic diversity at each locus was determined by polymorphism information content (PIC). The positions of SNP markers along chromosomes in terms of genetic distance (cM) were based on the 2015 wheat consensus genetic map (Wang et al., 2014). Markers were removed from the dataset if they were either monomorphic, showed more than $20 \%$ missing values, had ambiguous SNP calling or exhibited allele frequencies of less than 5\% (minor alleles).

\section{Statistical Analysis \\ Phenotypes}

Phenotypic data were analyzed with XLSTAT software 2010. Analyses of variance (ANOVA) and co-efficients of correlation were calculated for all traits.

\section{Population Structure and Kinship Analysis}

Population structure was estimated with 1000 unlinked SNP markers using STRUCTURE software 2.3.3, which implements a model-based Bayesian cluster analysis (Pritchard et al., 2000). The STRUCTURE procedure organizes population entries into $n$ cluster to form a structure matrix (Q-matrix). A putative number of subpopulations ranging from $k=1$ to 15 was assessed using 100,000 burn-in iterations followed by 500,000 recorded Markov-Chain iterations. To estimate the sampling variance (robustness) of inferred population structure, 10 independent runs were carried out for each $\mathrm{k}$. K was estimated using an adhoc statistic $\Delta \mathrm{K}$ based on the rate of change in log probability of data between successive values (Evanno et al., 2005; Quraishi et al., 2011). LD among markers was calculated using observed vs. expected allele frequencies of the markers in TASSEL v.5.0. Only mapped markers were used for LD calculation both for the entire panel and for model-based subgroups. The critical $r^{2}$-value beyond which LD is due to true physical linkage was determined by taking the 95th percentile of the square root transformed $r^{2}$ data of unlinked markers (Breseghello and Sorrells, 2006). The percentage of marker pairs significant at different critical $r^{2}$ values $(0.2$ and 0.2641$)$ and $P<0.001$ was determined for each chromosome to compare the degree of LD among genes.

\section{Association Analysis}

For best linear unbiased estimates, a mixed linear model (MLM) procedure was used, where the genotypes, replications, rows, and columns were considered as fixed in the model for each environment. MLM was also used to check statistically significant differences among the genotypes for each trait, whereas the Best Linear Unbiased Predictions (BLUPs) and variance components were acquired for all traits. The unified mixed model approach (Q+K model) of Yu and Buckler (2006) was applied to the data using TASSEL Standalone v.5.0 to estimate marker-phenotype associations. The already estimated population structure (Q) and relative kinship matrix $(\mathrm{K})$ were used in a MLM to test marker trait associations. Both phenotypic and genotypic data were imputed and filtered to reduce the data tree. The association between genotypic and phenotypic data was analyzed using the kinship matrix in MLM to control background variation. In order to account for the combined effect of such relatedness factors, kinship, and Q matrix were included as covariates in the regression model that defined the correlation between genotype and phenotype in association analysis (Quraishi et al., 2011). False discovery rate (FDR) analyses were conducted using QVALUE in R (Storey and Tibshirani, 2003).

\section{Gene Annotation and Synteny of MTA}

The flanking sequences of SNPs associated with traits were obtained from the Wheat 90K SNP array database (Wang et al., 2014). Gene ontology (GO) was assessed using BLAST2GO v.3 software (https://www.blast2go.com/), and SNPs were further annotated using the TriAnnot Pipeline in the International Wheat Genome Sequencing Pipeline.

A chromosome-based draft sequence of the hexaploid bread wheat was recently published (The International Wheat Genome Sequencing Consortium (IWGSC), 2014). Ditelosomic stocks of Chinese Spring wheat were used to isolate, sequence, and assemble de novo each individual chromosome arm, except for $3 \mathrm{~B}$, which was isolated and sequenced as a complete chromosome. Markers sequences were masked for repeat elements using a repeat masked database (http://www. girinst.org/server/RepBase/). Sequences of SNP markers linked with yield traits (henceforth: MTA) were BLASTed against wheat contigs of using a described previously methodology (Salse et al., 2008, 2009; Bolot et al., 2009). Sequences of Brachypodium distachyon, rice, sorghum pseudomolecules (builds Brachypodium 1.2 from http://www.brachypodium.org, Osativa_120 from http://phytozome.jgi.doe.gov/pz/portal.html, and Sorghum 1.0 from http://genome.jgi-psf.org/Sorbi1/Sorbi1. info.html) were then aligned against the wheat contigs and simultaneously against the identified MTA of all the traits. The criteria for alignment were escalated by considering three parameters reported in Salse et al. (2009), that is, AL (aligned length of sum of all HSP), CIP (cumulative identity percentage), and CALP (cumulative alignment length percentage). These parameters were applied to all BLAST alignments in the study. 


\section{Results}

\section{Phenotypic Evaluation}

The planting sites were located in the rainfed agroclimatic zone with reliability on rainfall, with 400,406 , and $560 \mathrm{~mm}$ in $2011-$ 12, 2012-2013, and 2013-2014 seasons, respectively. Release year of cultivars had significant impact on phenotypic variation $(P<0.01)$. ANOVA showed significant differences $(P<$ 0.01 ) among genotypes for most of the traits (Table 1). DH was non-significant in 2011-12 and 2012-13 seasons, falling within a range of only 7 and 8 days, respectively. Average GY during the three seasons ranged from 445.3 to $1787.6 \mathrm{~g}$ $\mathrm{m}^{-2}$. DH in 2013-14 (107.9 days) was longer than in 201112 and 2012-13 (91.4 and 97.4 days, respectively). However, BY was lowest in the third year $\left(691.2 \mathrm{~g} \mathrm{~m}^{-2}\right)$ due to lack of rain at the early growth stage. $\mathrm{PH}$ was significantly higher in 2013-14 $(93.3 \mathrm{~cm})$, while TGW was higher in year 2012-13 (Table 1).

GY was positively correlated with TGW $(r=0.70)$, $\mathrm{BY}(r=0.85)$, and $\mathrm{HI}(r=0.73)$ and (Table 2 and Supplementary Figure 1). PH and GY were not significantly correlated $(r=0.14)$, but $\mathrm{PH}$ was significantly correlated with TGW $(r=0.35)$ and BY $(r=0.24)$. Other correlations were non-significant or significant with very small $r$-value.

\section{Analysis of SNP Markers}

Among the 81,000 SNPs in the 90K infinium assay, $596(0.7 \%)$ were monomorphic and 19,810 (23.9\%) had poor quality, thus were excluded from the analysis. The remaining 60,594 (69.1\%) were further reduced to 14,960 (18.4\%) by eliminating markers with minor allele frequencies (MAF, $\leq 0.03$ ) and minimum counts of $80 \%$. SNP dataset can be requested for future research via email.

A genetic framework map of all 21 wheat chromosomes was constructed using the 14,960 polymorphic SNPs projected onto the consensus map (Wang et al., 2014), resulting in an average of 712 markers per chromosome. However, the marker density for the D-subgenome was relatively poor with an average of 484 markers per chromosome. In total, the polymorphic markers spaned over a genetic distance of $3705 \mathrm{cM}$, with an average density of $0.13 \mathrm{cM}$ per marker.

\section{Population Structure and Kinship Matrix}

The number of subgroups $(\mathrm{K})$ were estimated based on the rate of change in the log probability of data between successive $K$-values. In the plot of $\mathrm{K}$ against $\Delta \mathrm{K}$, a break in the slope was observed at $K=7$ followed by flattening of the curve (Figure 1). This indicated that the cultivars could be divided into seven sub-groups. Group I included post-Green Revolution

TABLE 1 | Basic statistics for nine yield components in historical wheat cultivars evaluated in 3 years.

\begin{tabular}{|c|c|c|c|c|c|c|}
\hline Trait ${ }^{a}$ & \multicolumn{2}{|c|}{ 2011-12 } & \multicolumn{2}{|c|}{ 2012-13 } & \multicolumn{2}{|c|}{ 2013-14 } \\
\hline DM (days) & 124.3-139 & 133.3 & 130.3-145 & 139.3 & 134-165 & 140.9 \\
\hline $\mathrm{PH}(\mathrm{cm})$ & $62-110$ & 81.2 & $59-120$ & 86.7 & $62-123$ & 93.3 \\
\hline GpS & $21-72$ & 44.3 & $27-81$ & 48.7 & $19-68$ & 45.9 \\
\hline TGW (g) & $16.4-51.5$ & 35.5 & $19.9-49.9$ & 31 & $17.4-51.6$ & 33.4 \\
\hline GY $\left(g^{-2}\right)$ & $224.3-518.5$ & 341 & $179.4-642.2$ & 301.2 & 139-843.6 & 352 \\
\hline $\mathrm{BY}\left(\mathrm{g} \mathrm{m}^{-2}\right)$ & $523.2-1043.3$ & 704.5 & $420.1-1229.8$ & 775.5 & $321.5-1623.2$ & 691.2 \\
\hline $\mathrm{HI}$ & $0.1-0.38$ & 0.3 & $0.1-0.4$ & 0.2 & $0.1-0.4$ & 0.29 \\
\hline
\end{tabular}

${ }^{a} D H$, Days to heading; DM, Days to maturity; PH, Plant height; GpS, Grains per spike; SN, Spike density; TGW, Thousand grain weight; GY, Grain yield; BY, Biological yield; and HI, Harvest index.

TABLE 2 | Pearson's coeffients of correlation between yield components based on data averaged over years.

\begin{tabular}{|c|c|c|c|c|c|c|c|c|}
\hline Trait $^{a}$ & DH & DM & PH & SN & GPS & TGW & GY & BY \\
\hline DM & 0.97 & & & & & & & \\
\hline $\mathrm{PH}$ & -0.07 & -0.09 & & & & & & \\
\hline GPS & 0.22 & 0.18 & -0.10 & 0.19 & & & & \\
\hline TGW & -0.09 & -0.13 & 0.35 & 0.14 & 0.12 & & & \\
\hline $\mathrm{HI}$ & -0.03 & -0.06 & 0.20 & 0.08 & 0.13 & 0.67 & 0.73 & 0.43 \\
\hline
\end{tabular}

Values in bold are different from $0, P<0.05$.

a See the footnote of Table 1 for abbreviations. 


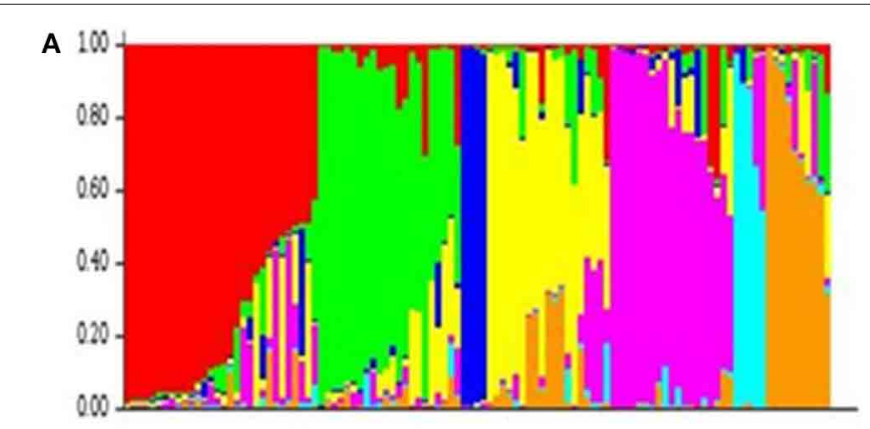

B

FIGURE 1 | Population structure of association mapping pannel based on unlinked SNP marker. (A) Plot of the scaled average logarithm of the probability of data likelihood $[\mathrm{LnP}(\mathrm{D})]$ and delta $\mathrm{K}(\Delta \mathrm{K})$ with $\mathrm{K}$ allowed to range from 2 to 15. (B) Membership co-efficient (Q-value) where each horizontal line represents one wheat line and partitioned into seven sub-populations.

cultivars selected for irrigated areas, group II included postGreen Revolution cultivars adapted for rainfed areas, group III were landraces and their derivatives, group IV were derivatives of Green-Revolution cultivars, group V included Green Revolution cultivars adapted from CIMMYT, group VI were post-Green Revolution cultivars from CIMMYT, and group VII included elite cultivars with an Inqalab-91 background. Almost 65\% of the population showed admixture trend, whereas only $35 \%$ originated from a single genetic background. Linkage disequilibrium (LD) analysis performed on all entries indicated the highest $\mathrm{LD}$ in the $\mathrm{B}$ genome, followed by $\mathrm{D}$ and then $\mathrm{A}$ genomes. The $\mathrm{B}$ genome had the highest $\mathrm{LD}$ in chromosome $1 \mathrm{~B}$ due to the $1 \mathrm{~B} .1 \mathrm{R}$ translocation. $\mathrm{LD}$ decay rate for the $\mathrm{B}$ genome was $25 \mathrm{cM}$ followed by $\mathrm{D}(20 \mathrm{cM})$ and $\mathrm{A}$ genomes $(7 \mathrm{cM})$. The frequency of physically linked locus pairs in significant $\mathrm{LD}$ was $31 \%$ overall $\left(r^{2}=0.2\right)$, among which the $\mathrm{D}$ genome had the highest proportion of marker pairs in LD (41\%), followed by $\mathrm{B}(35 \%)$ and A (25\%) genome. The estimated average $r^{2}$ for unlinked loci was 0.024 . Chromosome $6 \mathrm{D}$ had the maximum number of marker pair in LD (73\%), followed by 2D (48\%) and $1 \mathrm{~B}(46 \%)$. LD decreased with increasing genetic distance between marker loci. In all three cases, the $r^{2}$ declined within $12 \mathrm{cM}$ below critical values. In GWAS, there are two ways to account for confounding effect of population structure: (i) statistically accounting population structure, and (ii) carefully selection of the association mapping panel to reduce the range of phenology. We employed first strategy because the number of cultivars released in Pakistan were not sufficient for further selection based on phenology.

\section{Marker-trait Associations for Yield Related Traits}

A total, 2094 MTA were detected at $-\log P>3$ using MLM; however, only 44 MTAs with $-\log \mathrm{P}>4$ were considered to avoid false positive impact of alleles (Table 3 ). The highest numbers of MTAs were detected for PH (10) and TGW (10), followed by GY (5), BY (5), DH (5), DM (3), SN (3) and HI (3). The highest numbers of MTAs were identified on chromosomes $2 \mathrm{~B}$ (6) and 5B (6), followed by $1 \mathrm{~A}(5)$ and $2 \mathrm{~A}(5)$, whereas no MTA was found on chromosomes $1 \mathrm{D}, 2 \mathrm{D}, 3 \mathrm{D}$, and $5 \mathrm{D}$. The $\mathrm{D}$ genome had the lowest number of MTAs (4), whereas the B genome had the highest number (23), followed by the A genome (17). Multitrait loci were detected on chromosome $1 \mathrm{~A}$ (BY and GY), 1B (DH and $\mathrm{DM}), 2 \mathrm{~B}(\mathrm{DH}, \mathrm{DM}$, and $\mathrm{PH}), 4 \mathrm{~B}$ (BY and GY), and $6 \mathrm{~B}(\mathrm{HI}, \mathrm{BY}$, and GY). MTAs on chromosomes $5 \mathrm{~B}$ and $6 \mathrm{~B}$ were frequently detected for different traits across years. Haplotypes generated for all yield components are compared based on-log $P$-values on bin based synteny maps of wheat, rice, and sorghum (Figure 2).

\section{Gene Annotation}

Gene ontology (GO) of 44 MTA sequences were assessed using BLAST2GO v.3 software and SNPs were further annotated using the TriAnnot Pipeline. Twenty (54.5\%) SNPs were annotated as present within genes (Table 3). The transcripts of these genes encoded binding proteins (3), response to stimulus protein (3), catalytic activity proteins (2), cellular proteins (2), organelle related proteins (1), a single-organism process protein (1), a cellular process protein (1), a metabolic process proteins (1), a membrane protein (1), a reproductive process protein (1), a developmental process protein (1), and a multicellular organismal process protein (1).

\section{Synteny-based Dissection of Yield Components Wheat Cultivars}

The alignment of traits-associated SNPs to 454-wheat contigs and their synteny to rice, Brachypodium, and sorghum aided identification of orthologous regions. Out of 2094 SNPs associated with traits, 540 were aligned against contigs with cutoff values of 70\% CIP and 70\% CALP. These assembled contigs were aligned with 240 rice, 388 Brachypodium, and 210 Sorghum annotated genes. However, only 16 out of 44 stable MTAs could be aligned against wheat contig sequences. Seventeen markers colocalized with five annotated genes of rice, nine of sorghum, and 10 of Brachypodium (Table 3).

\section{Effects of Favorable Alleles on Important Agronomic Traits}

The favorable alleles of significantly associated SNPs had minor additive effects on DH, PH, TGW, and GY (Figure 3). DH and $\mathrm{PH}$ were decreased by increasing the number of favorable alleles 


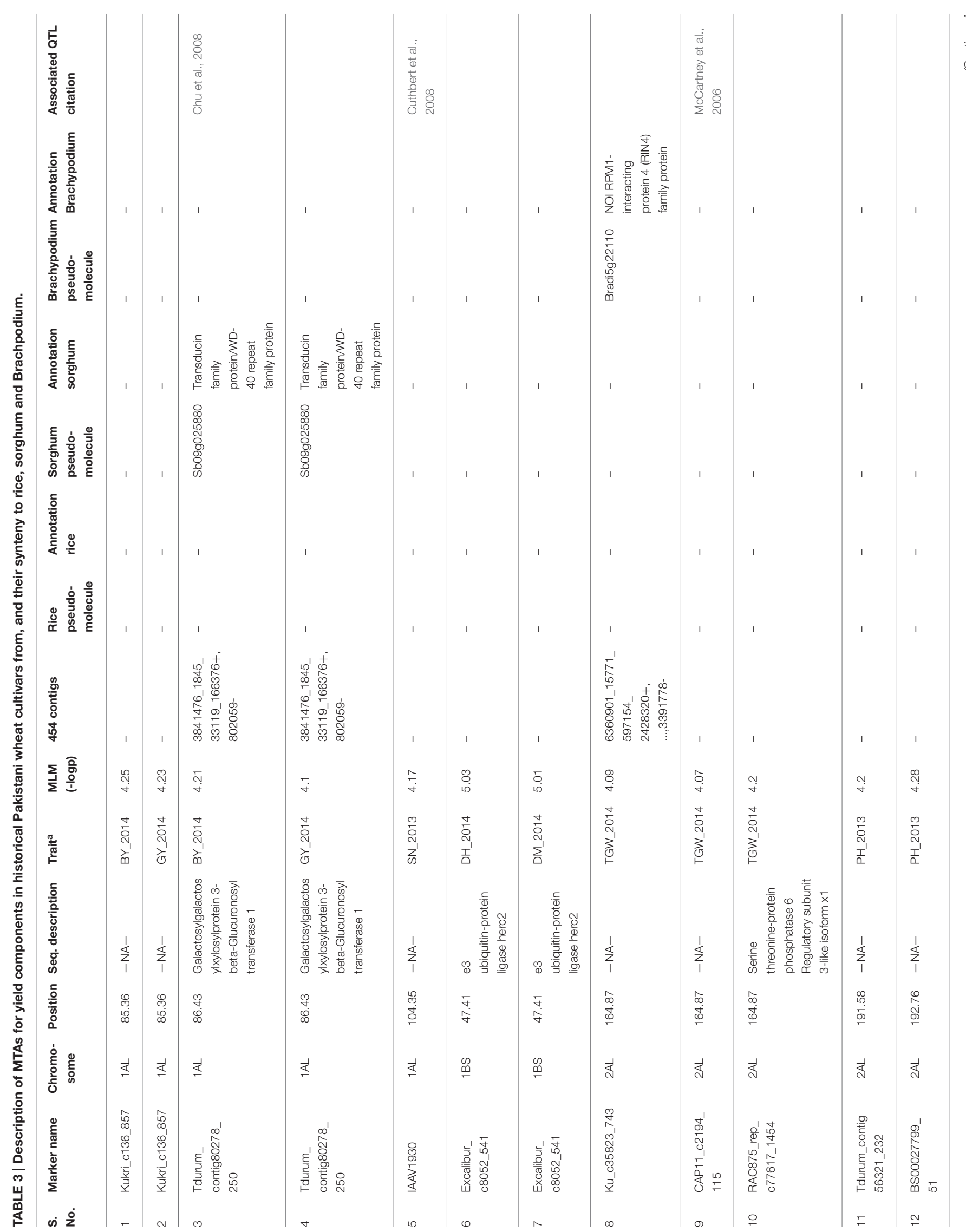




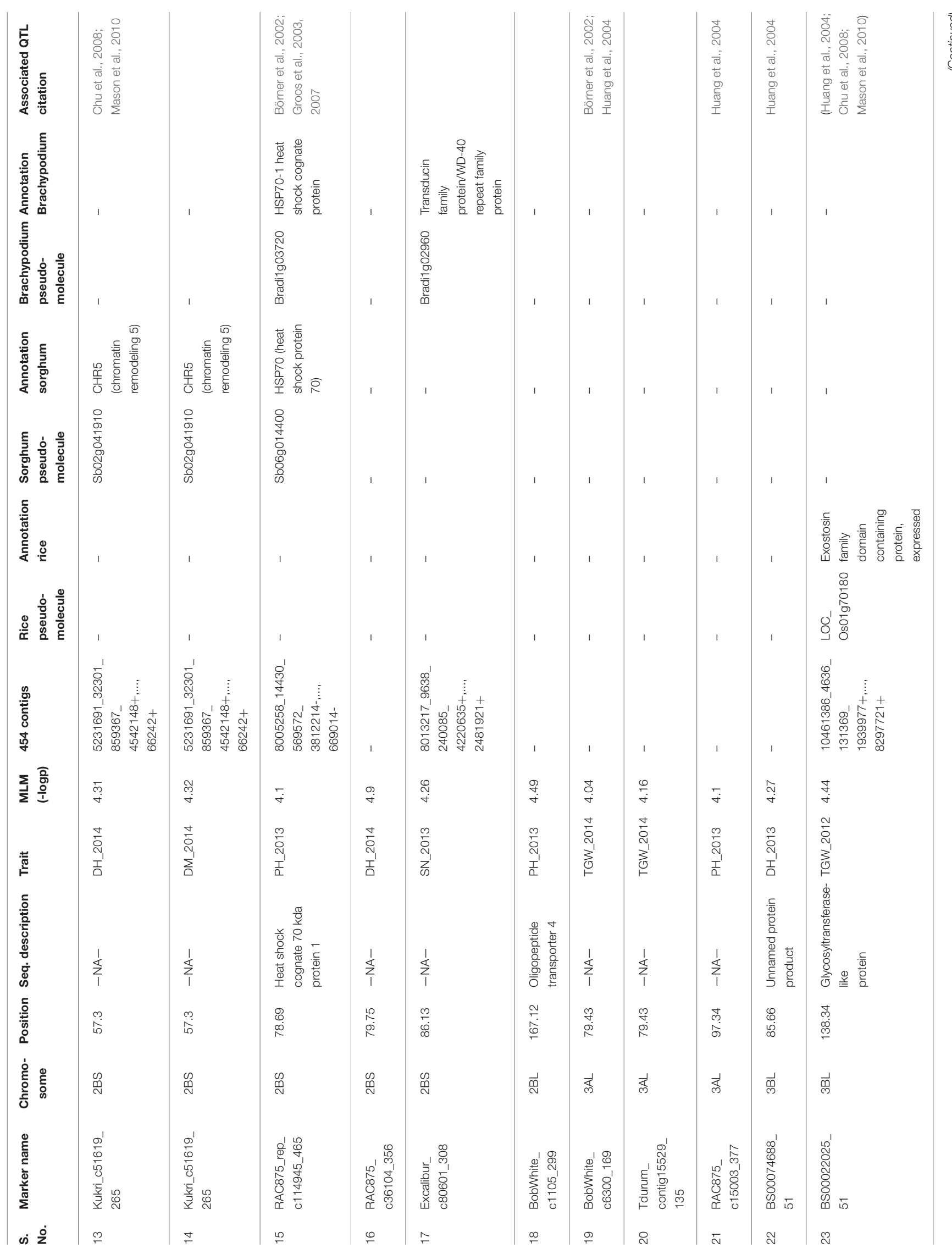




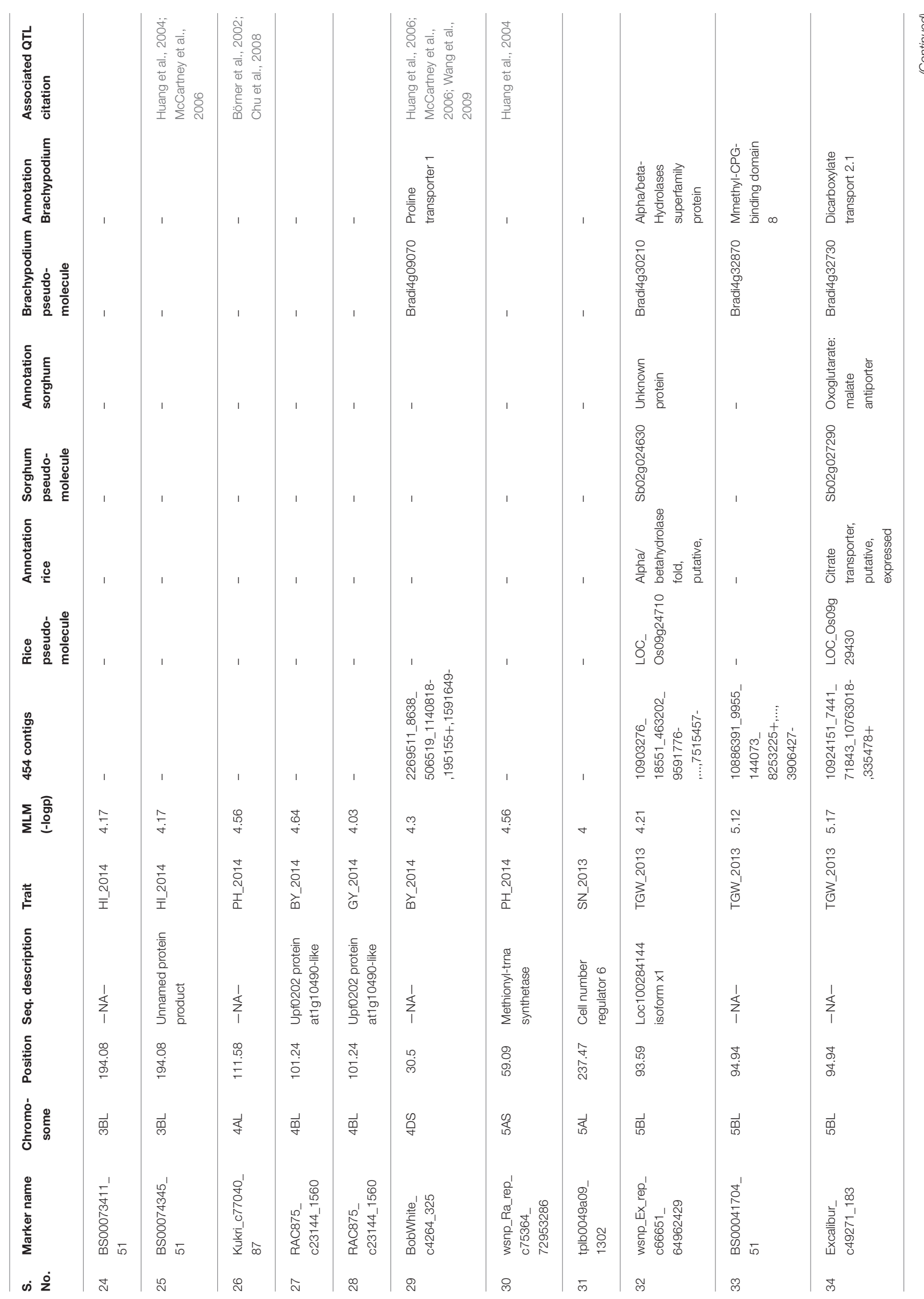




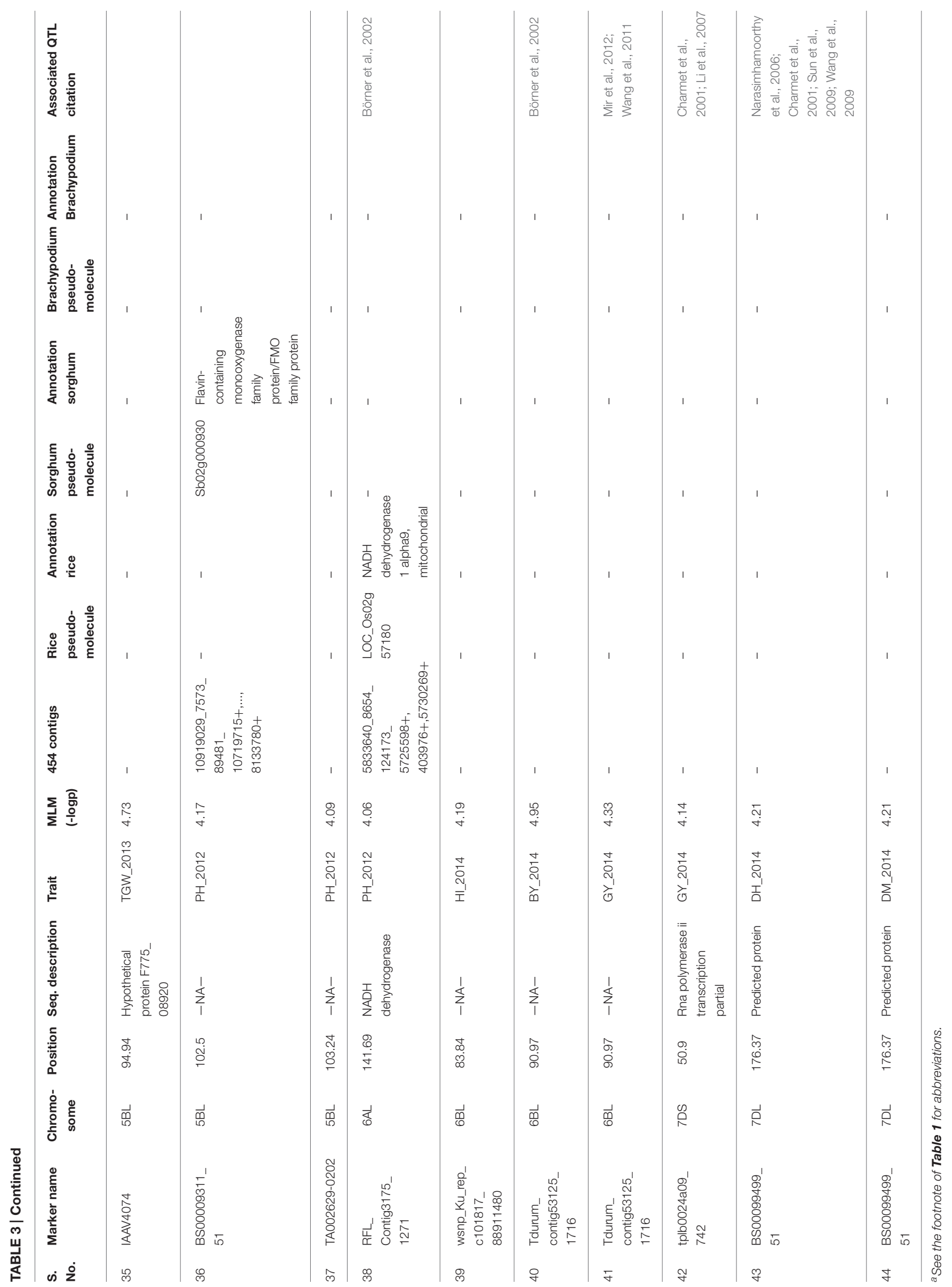




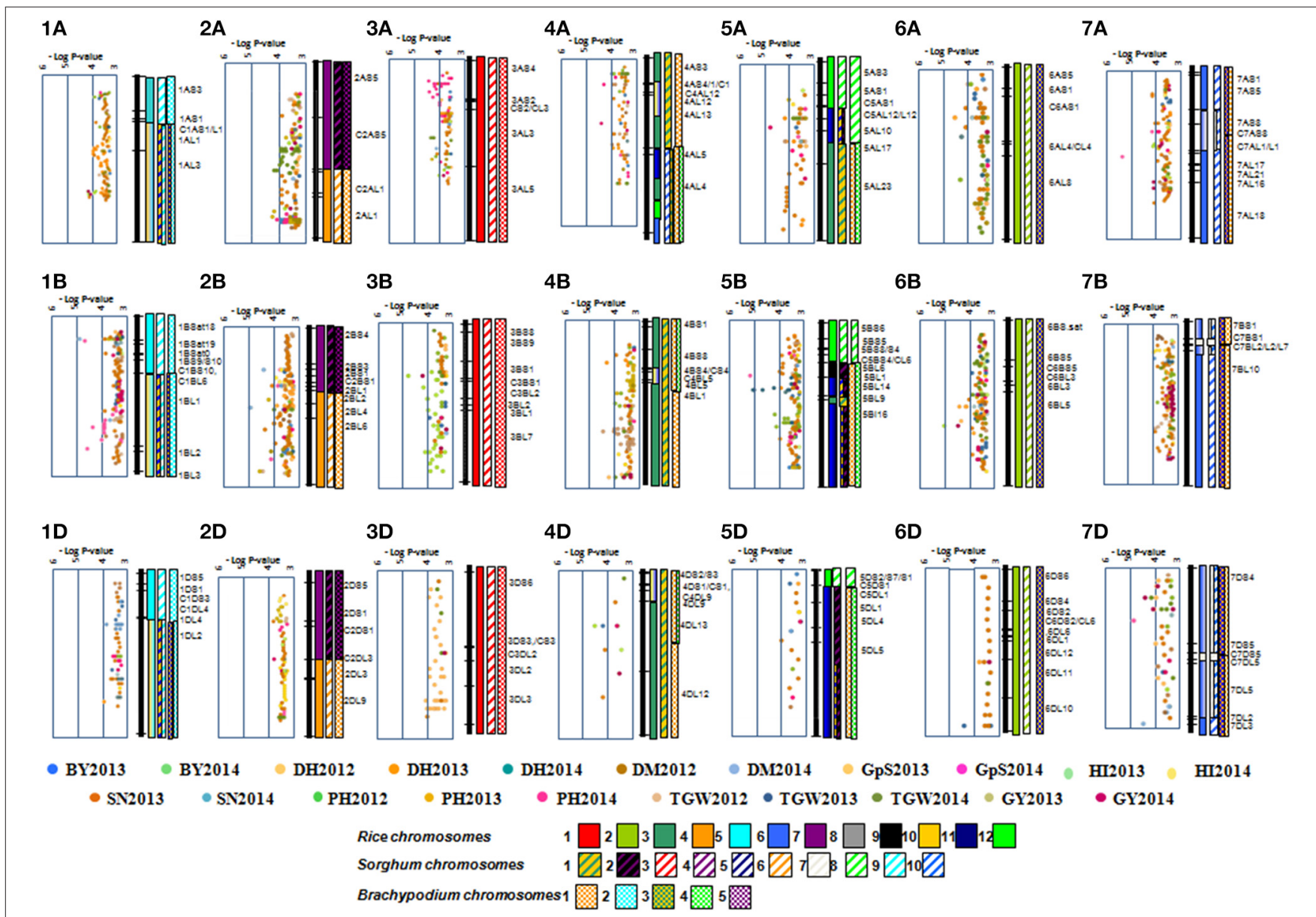

FIGURE 2 | Distribution of 2203 MTA on wheat chromosomes bin based on their-log $\boldsymbol{P}$-value. Orthologous chromosome are presented in different color codes.

and linear regressions (R2) between numbers of favorable alleles and phenotype were 0.15 and 0.06 , respectively. Similarly, the higher frequency of favorable alleles of associated SNPs additively enhanced TGW and GY with R2 of 0.22 and 0.32 , respectively (Figure 3). There had been no selection pressure on any of these favorable alleles, which were evenly distributed across old and modern cultivars. However, the frequency of favorable alleles for $\mathrm{DH}, \mathrm{PH}, \mathrm{TGW}$, and GY were slightly higher in cultivars released post-2000, compared to those released before 2000 (Table 3). $\mathrm{DH}$ and $\mathrm{PH}$ fell from 108.7 to 106.7 days and 94.0 to $91.8 \mathrm{~cm}$, and TGW and GY increased from 32.2 to $36.4(\mathrm{~g})$ and 422.4 to $521.5\left(\mathrm{~g} \mathrm{~m}^{-2}\right)$ in pre-2000 compared to post-2000 cultivars, respectively (Table 4 ).

\section{Discussion}

\section{Genetic and Phenotypic Structure of Historical Wheat Cultivars}

The significant proportion of wheat cultivars from Pakistan are derived from CIMMYT germplasm, either as directly released cultivars, or as parents in crossing programs that led to new cultivars. Population structure provided the confirmatory evidence that CIMMYT cultivars like Mexipak65, Pavon76 and SeriM82 (syn. Pak-81) appeared in same sub-populations along with Pakistani cultivars. Secondly, the population structure clearly dissected the cultivars released for irrigated and rainfed environments, indicating different genetic backgrounds used in developing cultivars for these two regions. 1BL.1RS translocation lines from CIMMYT are important breeding source which adapted very well in rainfed environments of Pakistan. Earlier studies reported that 1BL.1RS lines had higher root and shoot dry weight under drought treatments and an increased root/shoot ratio (Hoffmann, 2008). In addition, research has shown increased efficiencies of light conversion, particularly with the 1BL.1RS translocation, hence biomass was increased. The 1BL.1RS translocation has been used intensively in wheat breeding, but less at CIMMYT in recent times, due to its negative effect on quality (Sukumaran et al., 2015). However, recent report indicated the presence of $1 \mathrm{~B} .1 \mathrm{R}$ translocation in cultivars released recently in Pakistan (Rasheed et al., 2015). Population structure based on SNP markers also identified the breeding activities independent of 

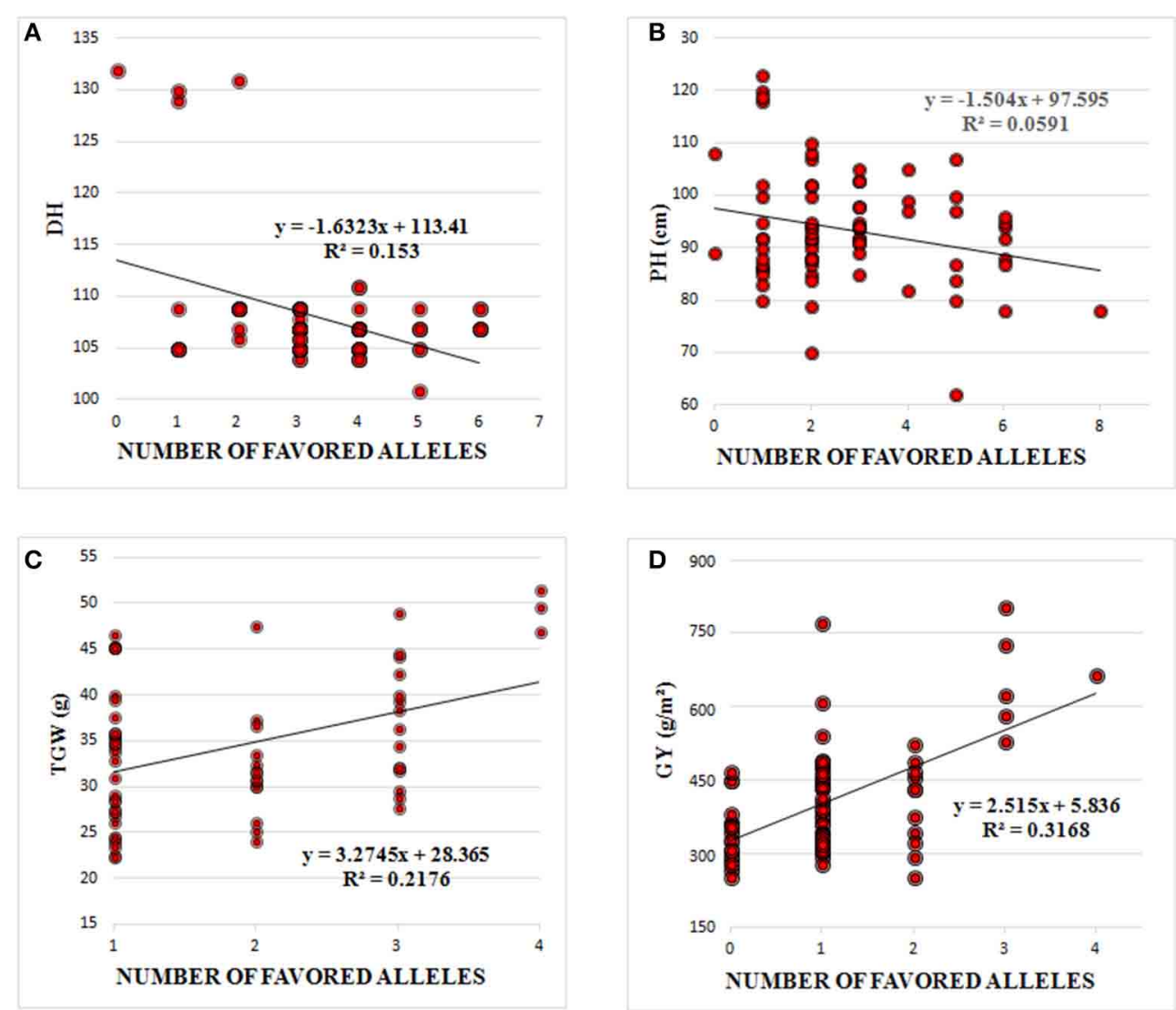

FIGURE 3 | Linear regression between number of favored alleles and (A) days to heading (DH), (B) Plant Height (PH), (C) Thousand Grain Weight (TGW), and (D) Grain Yield (GY).

TABLE 4 | Percentage frequency of favorable alleles for DH, days to heading; PH, plant height; TGW, thousand grain weight; and GY, grain yield in cultivars released before and after 2000.

\begin{tabular}{|c|c|c|c|c|c|c|c|c|}
\hline Trait $^{\mathrm{a}}$ & Cultivar group ${ }^{\star *}$ & Mean & \multicolumn{6}{|c|}{ Frequency $(\%)$ of favorable alleles ${ }^{*}$} \\
\hline & Post-2000 & 106.9 & 0 & 4.9 & 22 & 39 & 19.5 & 12.2 \\
\hline \multirow[t]{2}{*}{$\mathrm{PH}$} & Pre-2000 & 94.05 & 2.9 & 23.5 & 26.5 & 25 & 7.4 & 7.4 \\
\hline & Post-2000 & 91.85 & 0 & 22 & 39 & 14.6 & 4.9 & 9.8 \\
\hline TGW & Post-2000 & 36.44 & 17.1 & 43.9 & 22 & 12.2 & 4.9 & 0 \\
\hline \multirow[t]{2}{*}{ GY } & Pre-2000 & 422.4 & 23.5 & 57.4 & 13.2 & 5.9 & 0 & 0 \\
\hline & Post-2000 & 521.5 & 34.1 & 43.9 & 9.8 & 7.3 & 4.9 & 0 \\
\hline
\end{tabular}

${ }^{*}$ Frequency refers to number of cultivars with $0,1,23,4$, and 5 favorable alleles.

${ }^{\star *}$ Cultivar groups refers to 68 cultivars released before year 2000 (pre-2000) and 41 cultivars released after 2000 (post-2000).

a See the footnote of Table 1 for abbreviations.

CIMMYT germplasm by clustering cultivars in group VII. This group clustered together the Inqalab-91, a leading, and predominant cultivar, and its derivatives. Another important finding is the separate clustering of landraces, indicating the limited use of landraces in recent breeding in Pakistan, in agreement with our recent findings based on analysis of functional genes (Rasheed et al., 2015).
Phenotypic characterization for yield-related traits indicated that historical germplasm has significant variation in traits like TGW, GpS, and SN (Table 1). Therefore, genetic dissection of important economic traits in historical cultivars could be useful for utilization in wheat genetic improvement. Nine traits selected to dissect yield and some were positively correlated with GY as previously reported (Dodig et al., 2012; Sukumaran et al., 2015). 
Our results on LD using a 90K SNP assay were partially different with previous reports. $\mathrm{LD}$ was higher in the $\mathrm{B}$ and $\mathrm{D}$ genomes than in the A genome. This was largely due to selection of Glu$B 1$ alleles that are important for chapatti making, and frequent presence of the 1B.1R translocation in cultivars grown after 1981 (Rasheed et al., 2015). However, higher LD involving SNPs in the $\mathrm{D}$ genome is in agreement with previous studies and is due to limited infusion of $A$. tauschii germplasm in the evolution of bread wheat (Wang et al., 2013).

\section{Marker-trait Associations}

The ultimate breeding objective is the higher gains for GY, a very complex trait with low heritability. In contrast, yield components like thousand kernel weight (not spike number) are more stable across environments and have higher heritabilities (Lopes et al., 2014). Therefore, identifying stable QTL for yield components having higher correlation with GY can be helpful to manipulate GY. In this study, MTAs involving GY and related traits were identified on all wheat chromosomes, including consistent and environmentally specific MTAs. They are compared to MTAs identified in other studies (Table 3 and Supplementary Data Sheet 1), and 18 MTAs co-localized with QTL identified in earlier studies. It is important to mention that phenotypic trials were conducted in rainfed environment, therefore MTAs identified in this study are important because they may be linked to minor genes adaptation to rainfed environments.

MTAs for DH were identified on chromosome 1BS, 2BL, $2 \mathrm{BS}$, and 7DL. Those present on 1BS, 2BS, and 7DL also had pleitropic effect on DM. The MTA for DH and DM on chromosome 2BS corresponded to a previously identified chromosomal region (Chu et al., 2008; Mason et al., 2010). Similarly, the MTA linked to DH and DM on 7DL was reported earlier in biparental QTL analyses in several studies (Charmet et al., 2001; Narasimhamoorthy et al., 2006; Wang et al., 2009). $\mathrm{PH}$ is another important trait to deploy especially in rainfed environments. Semi-dwarf cultivars were major contributors to the success of the Green Revolution in the Indian sub-continent. Stable MTAs linked to PH on chromosomes 2AL, 2BL, 3AL, 4AL, $5 \mathrm{AS}, 5 \mathrm{BL}$, and $6 \mathrm{AL}$, were identified in the current study. An MTA for $\mathrm{PH}$ on chromosome $2 \mathrm{BL}$ was within confidence intervals of previously identified QTL (Börner et al., 2002; Groos et al., 2003, 2007). Similarly, MTAs on chromosome 5AS and 6AL are most likely the QTL reported earlier (Börner et al., 2002; Huang et al., 2004; Sukumaran et al., 2015). The MTA for PH on chromosome $3 \mathrm{~A}$ corresponded to OsGA2ox3 (Sakamoto et al., 2004), the 4A MTA corresponded to an ent-kaurenic acid oxidase (KAO) gene in the gibberellin metabolic pathway affecting $\mathrm{PH}$ (Khlestkina et al., 2010), and a chromosome 5A MTA corresponded to the Rht9 locus (Ellis et al., 2005). Although Rht-B1 and Rht-D1 on chromosomes $4 \mathrm{~B}$ and $4 \mathrm{D}$ were significantly associated with $\mathrm{PH}$ in historical Pakistani cultivars (Rasheed et al., 2015), we found no MTAs on chromosomes 4B and 4D indicated SNPs linked to these genes were either not present in $90 \mathrm{~K}$ assay or were excluded during quality control.

MTAs for TGW were present on chromosomes $2 \mathrm{AL}, 3 \mathrm{AL}$, 3BL, and 5BL. MTA on 5BL had the pleitropic effect on $\mathrm{PH}$ and TGW, and can be important target to manipulate both traits simultaneously. Chromosome 2AL had three MTAs at the same position within a region previously reported for a biparntal population (McCartney et al., 2006). Similarly, MTAs for SN were present on 1A, 2B, and 5A chromosomes. Previously, stable genomic regions on chromosomes $3 \mathrm{~B}, 5 \mathrm{~A}$, and $5 \mathrm{~B}$ have been implicated in yield and related traits (Pinto et al., 2010; Edae et al., 2014; Lopes et al., 2014). In CIMMYT germplasm, they are perhaps most important genomic regions associated with multiple yield related traits (Sukumaran et al., 2015). This is important to mention that TGW and grain number are the primary components of GY, and are usually negatively correlated in segregating populations. Therefore, it has been important and challenging strategy to identify the genomic regions enhancing TGW without significant reduction in grain number (Griffiths et al., 2015). In our study, the MTA associated with these two traits were independent of each other, however their allelic effects were minor, and the extent of trade-offs between grain numbers and TGW may be reduced. Although genetic gain for yield has been achieved by increasing grain number, however it is possible to produce high yielding cultivars with large grains. For example, CIMMYT cultivars Bavicora and Kambara have relatively large grains (Sayre et al., 1997). This has led to investigate the underlying genes controlling grain size and weight, and several genes have been documented recently (Valluru et al., 2014). The analysis of such functional genes for grain size and weight in same germplasm indicated that TaSus2-2B, TaGW2-6A, and TaGSD1 have larger effects on TGW as compared to TaCwi-2A and TaCKX-D1 (Rasheed et al., 2015). These functional genes and SNPs associated with TGW in this study can help in designing new strategies to accumulate favorable alleles for TGW in future wheat breeding.

MTA responsible for GY were identified on chromosomes $1 \mathrm{AL}, 4 \mathrm{BL}, 6 \mathrm{BL}$, and 7DL, and only 7DL MTA was reported in biparental QTL analyses (Charmet et al., 2001; Bossolini et al., 2007). MTAs associated with multiple traits and referred as pleiotropic MTAs were identified for GY and BY on chromosomes 1AL, 4BL, and 6BL. Same SNP marker was associated with GY and BY on chromosome 6BL at $90.9 \mathrm{cM}$, however, another MTA was identified for HI on chromosome $6 \mathrm{BL}$ at $83.8 \mathrm{cM}$. Given the LD decay of $8-10 \mathrm{cM}$ these regions are in strong $\mathrm{LD}$, and they may be controlled by the same locus.

\section{Annotation and Synteny of Trait Associated SNP}

Cloning and gene identification in wheat is a difficult task, but is becoming less daunting due to the extensive genomics efforts by the international wheat community. Although comparative genomics is a powerful tool in trait dissection, confirmation of the roles of individual genes will still be needed through functional validation. The large rainfed Indo-Pakistan plain is undergoing climate change. As mentioned above, the genomic regions identified in this study could be fruitful for future breeding programs due to their role in combating stresses created by climate change. Annotation of falking sequences and their syntenic relationship to the genes in rice, sorgum and Brachypodium confirmed our findings that these genomic regions encode proteins which are important components of 
pathways triggered in response to stressed environments. For example, aldehyde dehydrogenase (Yu et al., 2014), cell number regulator six protein (Guo et al., 2010), glycosyltransferase-like protein (Wang et al., 2015), molybdenum cofactor sulfurase (Lu et al., 2013), n-acetylglucosaminyltransferase III (Nguema-Ona et al., 2014), NADH dehydrogenase, and serine threonine-protein phosphatase six (Mao et al., 2010; Zhang et al., 2010a) were reported in earlier studies to be linked to plant metabolic stability. These genes are present in genomic regions associated with yield traits and can be considered possible candidate genes for yield improvement as well as for future cloning of these loci.

\section{Allelic Effects of Trait Associated SNPs}

The overall superiority of post-2000 cultivars highlights the considerable progress made during the past decade, and the significant improvement achieved for important economic traits like $\mathrm{DH}, \mathrm{PH}, \mathrm{TGW}$, and GY. There were minor additive relationships between numbers of favorable alleles and agronomic traits, indicating that genetic improvement of these traits were independent and therefore can be combined. Many of the identified MTAs seem to involve genes that are components of networks driven by the prevailing environmental plasticity and show little improvement in phenotypic stability. The results are also interesting in that none of the favorable alleles has been a breeding target during cutlivar development. This is in contrast to favorable alleles of functional genes for adaptability $(P p d-D 1$, Rht-B1, and Rht-D1) and TGW (TaGW2-6A and TaCKX6-D1) deployed in Pakistani wheat cultivars (Rasheed et al., 2015). In this situation, cultivars with maximum numbers of favorable alleles can be used as breeding resources and the present results may provide a basis to initiate genomic selection methods (Jannink, 2007) to maximize genetic gains.

\section{References}

Akhunov, E., Nicolet, C., and Dvorak, J. (2009). Single nucleotide polymorphism genotyping in polyploid wheat with the Illumina GoldenGate assay. Theor. Appl. Genet. 119, 507-517. doi: 10.1007/s00122-009-1059-5

Bennett, D., Izanloo, A., Reynolds, M., Kuchel, H., Langridge, P., and Schnurbusch, T. (2012). Genetic dissection of grain yield and physical grain quality in bread wheat (Triticum aestivum L.) under water-limited environments. Theor. Appl. Genet. 125, 255-271. doi: 10.1007/s00122-012-1831-9

Bolot, S., Abrouk, M., Masood-Quraishi, U., Stein, N., Messing, J., Feuillet, C., et al. (2009). The "inner circle" of the cereal genomes. Curr. Opin. Plant Biol. 12, 119-125. doi: 10.1016/j.pbi.2008.10.011

Bordes, J., Goudemand, E., Duchalais, L., Chevarin, L., Oury, F. X., Heumez, E., et al. (2014). Genome-wide association mapping of three important traits using bread wheat elite breeding populations. Mol. Breed. 33, 755-768. doi: 10.1007/s11032-013-0004-0

Bordes, J., Ravel, C., Jaubertie, J., Duperrier, B., Gardet, O., Heumez, E., et al. (2013). Genomic regions associated with the nitrogen limitation response revealed in a global wheat core collection. Theor. Appl. Genet. 126, 805-822. doi: $10.1007 / \mathrm{s} 00122-012-2019-\mathrm{z}$

Börner, A., Schumann, E., Furste, A., Cöster, H., Leithold, B., Röder, M., et al. (2002). Mapping of quantitative trait loci for agronomic important characters in hexaploid wheat(Triticum aestivum L.). Theor. Appl. Genet. 105, 921-936. doi: 10.1007/s00122-002-0994-1

Bossolini, E., Wicker, T., Knobel, P. A., and Keller, B. (2007). Comparison of orthologous loci from small grass genomes Brachypodium and rice:

\section{Conclusion}

GWAS identified chromosomal regions associated with yield traits in historical germplasm deployed in Pakistan. Annotation and comparative genomics assigned 14 of those MTAs to different metabolic functions which have implications to combat stressed environments. These MTAs can be important targets for markerbased breeding and fine mapping of functional genes after further validation.

\section{Acknowledgments}

We are grateful to Prof. R. A. McIntosh at Plant Breeding Institute, University of Sydney, for suggestions on the manuscript.

\section{Supplementary Material}

The Supplementary Material for this article can be found online at: http://journal.frontiersin.org/article/10.3389/fpls.2015. 00743

Supplementary Figure 1 | Frequency distribution, correlation, and scatter plot of mean values of nine yield components in historical wheat cultivars Days to heading (DH), days to maturity (DM), plant height (PH), grains per spike (GpS), spike density (SN), thousand grain weight (TGW), grain yield (GY), biological yield (BY), and harvest index (HI).

\section{Supplementary Table 1 | Passport data of historical set of Pakistan decrypting for each cultivar; its synonym, release year, released by, CIMMYT Br Line, plant height, pedigree and selection History.}

Supplementary Data Sheet 1 | Description of annotation and function of annotated MTAs.

implications for wheat genomics and grass genome annotation. Plant J. 49, 704-717. doi: 10.1111/j.1365-313X.2006.02991.x

Breseghello, F., and Sorrells, M. E. (2006). Association mapping of kernel size and milling quality in wheat (Triticum aestivum L.) cultivars. Genetics 172, 1165-1177. doi: 10.1534/genetics.105.044586

Charmet, G., Robert, N., Perretant, M., Gay, G., Sourdille, P., Groos, C., et al. (2001). Marker assisted recurrent selection for cumulating QTLs for bread-making related traits. Euphytica 119, 89-93 doi: 10.1023/A:1017577 918541

Chu, C. G., Xu, S. S., Friesen, T. L., and Faris, J. D. (2008). Whole genome mapping in a wheat doubled haploid population using SSRs and TRAPs and the identification of QTL for agronomic traits. Mol. Breed. 22, 251-266 doi: 10.1007/s11032-008-9171-9

Cuthbert, J. L., Somers, D. J., Brûlé-Babel, A. L., Brown, P. D., and Crow, G. H. (2008). Molecular mapping of quantitative trait loci for yield and yield components in spring wheat (Triticum aestivum L.). Theor. Appl. Genet. 117, 595-608 doi: 10.1007/s00122-008-0804-5

Dodig, D., Zorić, M., Kandić, V., Perović, D., and Šurlan-Momirović, G. (2012). Comparison of responses to drought stress of 100 wheat accessions and landraces to identify opportunities for improving wheat drought resistance. Plant Breed. 131, 369-379. doi: 10.1111/j.1439-0523.2011. 01941.x

Dreisigacker, S., Shewayarga, H., Crossa, J., Arief, V. N., DeLacy, I., Singh, R. P., et al. (2012). Genetic structure of the CIMMYT international yield trial targeted to irrigated environments. Mol. Breed. 29, 529-541. doi: 10.1007/s11032-0119569-7 
Edae, E. A., Byrne, P. F., Haley, S. D., Lopes, M. S., and Reynolds, M. P. (2014). Genome-wide association mapping of yield and yield components of spring wheat under contrasting moisture regimes. Theor. Appl. Genet. 127, 791-807. doi: 10.1007/s00122-013-2257-8

Ellis, M. H., Rebetzke, G. J., Azanza, F., Richards, R. A., and Spielmeyer, W. (2005). Molecular mapping of gibberellin-responsive dwarfing genes in bread wheat. Theor. Appl. Genet. 111, 423-430. doi: 10.1007/s00122-005-2008-6

Evanno, G., Regnaut, S., and Goudet, J. (2005). Detecting the number of clusters of individuals using the software STRUCTURE: a simulation study. Mol. Ecol. 14, 2611-2620. doi: 10.1111/j.1365-294X.2005.02553.x

Griffiths, S., Wingen, L., Pietragalla, J., Garcia, G., Hasan, A., Miralles, D., et al. (2015). Genetic dissection of grain size and grain number trade-offs in CIMMYT wheat germplasm. PLOS ONE 10:e0118847. doi: 10.1371/journal.pone.0118847

Groos, C., Bervas, E., Chanliaud, E., and Charmet, G. (2007). Genetic analysis of bread-making quality scores in bread wheat using a recombinant inbred line population. Theor. Appl. Genet. 115, 313-323. doi: 10.1007/s00122-007-0563-8

Groos, C., Robert, N., Bervas, E., and Charmet, G. (2003). Genetic analysis of grain protein-content, grain yield and thousand-kernel weight in bread wheat. Theor. Appl. Genet. 106, 1032-1040. doi: 10.1007/s00122-002-1111-1

Guo, M., Rupe, M. A., Dieter, J. A., Zou, J., Spielbauer, D., Duncan, K. E., et al. (2010). Cell Number Regulator1 affects plant and organ size in maize: implications for crop yield enhancement and heterosis. Plant Cell 22, 1057-1073. doi: 10.1105/tpc.109.073676

Hoffmann, B. (2008). Alteration of drought tolerance of winter wheat caused by translocation of rye chromosome segment 1RS. Cereal Res. Commun. 36, 269-278. doi: 10.1556/CRC.36.2008.2.7

Huang, X. Q., Cloutier, S., Lycar, L., Radovanovic, N., Humphreys, D. G., Noll, J. S., et al. (2006). Molecular detection of QTLs for agronomic and quality traits in a doubled haploid population derived from two Canadian wheats (Triticum aestivum L.). Theor. Appl. Genet. 113, 753-766. doi: 10.1007/s00122-006-0346-7

Huang, X. Q., Kempf, H., Ganal, M. W., and Roder, M. S. (2004). Advanced backcross QTL analysis in progenies derived from a cross between a German elite winter wheat variety and a synthetic wheat (Triticum aestivum L.). Theor Appl. Genet. 109, 933-943. doi: 10.1007/s00122-004-1708-7

Jannink, J. L. (2007). Identifying quantitative trait loci by genetic background interactions in association studies. Genetics 176, 553-561. doi: 10.1534/genetics.106.062992

Khlestkina, E. K., Kumar, U., and Röder, M. S. (2010). Ent-kaurenoic acid oxidase genes in wheat. Mol. Breed. 25, 251-258. doi: 10.1007/s11032-009-9326-3

Langridge, P., and Reynolds, M. P. (2015). Genomic tools to assist breeding for drought tolerance. Curr. Opin. Biotechnol. 32, 130-135. doi: 10.1016/j.copbio.2014.11.027

Li, S., Jia, J., Wei, X., Zhang, X., Li, L., Chen, H., et al. (2007). A intervarietal genetic map and QTL analysis for yield traits in wheat. Mol. Breed. 20, 167-178. doi: 10.1007/s11032-007-9080-3

Liu, Y., He, Z., Appels, R., and Xia, X. (2012). Functional markers in wheat: current status and future prospects. Theor. Appl. Genet. 125, 1-10. doi: 10.1007/s00122012-1829-3

Liu, Z. H., Anderson, J. A., Hu, J., Friesen, T. L., Rasmussen, J. B., and Faris, J. D. (2005). A wheat intervarietal genetic linkage map based on microsatellite and target region amplified polymorphism markers and its utility for detecting quantitative trait loci. Theor. Appl. Genet. 111, 782-794. doi: 10.1007/s00122005-2064-y

Lopes, M., Dreisigacker, S., Peña, R., Sukumaran, S., and Reynolds, M. (2014). Genetic characterization of the Wheat Association Mapping Initiative (WAMI) panel for dissection of complex traits in spring wheat. Theor. Appl. Genet. 128, 453-464. doi: 10.1007/s00122-014-2444-2

Lu, Y., Li, Y., Zhang, J., Xiao, Y., Yue, Y., Duan, L., et al. (2013). Overexpression of Arabidopsis molybdenum cofactor sulfurase gene confers drought tolerance in maize (Zea mays L.). PLoS ONE 8:e52126. doi: 10.1371/journal.pone. 0052126

Mao, X., Zhang, H., Tian, S., Chang, X., and Jing, R. (2010). TaSnRK2.4, an SNF1type serine/threonine protein kinase of wheat (Triticum aestivum L.), confers enhanced multistress tolerance in Arabidopsis. J. Exp. Bot. 61, 683-696. doi: 10.1093/jxb/erp331

Mason, R., Mondal, S., Beecher, F. W., Pacheco, A., Jampala, B., Ibrahim, A. M. H., et al. (2010). QTL associated with heat susceptibility index in wheat (Triticum aestivum L.) under short-term reproductive stage heat stress. Euphytica 174, 423-436. doi: 10.1007/s10681-010-0151-x

McCartney, C. A., Somers, D. J., Lukow, O., Ames, N., Noll, J., Cloutier, S., et al. (2006). QTL analysis of quality traits in the spring wheat cross RL4452 x "AC Domain.” Plant Breed. 125, 565-575. doi: 10.1111/j.1439-0523.2006.01256.x

Mir, R. R., Kumar, N., Jaiswal, V., Girdharwal, N., Prasad, M., Balyan, H. S., et al. (2012). Genetic dissection of grain weight in bread wheat through quantitative trait locus interval and association mapping. Mol. Breed. 29, 963-972. doi: 10.1007/s11032-011-9693-4

Narasimhamoorthy, B., Gill, B. S., Fritz, A. K., Nelson, J. C., and Brown-Guedira, G. L. (2006). Advanced backcross QTL analysis of a hard winter wheat x synthetic wheat population. Theor. Appl. Genet. 112, 787-796. doi: 10.1007/s00122-0050159-0

Nguema-Ona, E., Vicré-Gibouin, M., Gotté, M., Plancot, B., Lerouge, P., Bardor, M., et al. (2014). Cell wall O-glycoproteins and N-glycoproteins: aspects of biosynthesis and function. Front. Plant Sci. 5:499. doi: 10.3389/fpls.2014.00499

Pingault, L., Choulet, F., Alberti, A., Glover, N., Wincker, P., Feuillet, C., et al. (2015). Deep transcriptome sequencing provides new insights into the structural and functional organization of the wheat genome. Genome Biol. 16, 29-44. doi: 10.1186/s13059-015-0601-9

Pinto, R. S., Reynolds, M. P., and Mathews, K. L. (2010). Heat and drought adaptive QTL in a wheat population designed to minimize confounding agronomic effects. Theor. Appl. Genet. 121, 1001-1021 doi: 10.1007/s00122-010-1351-4

Poland, J. A., Brown, P. J., Sorrells, M. E., and Jannink, J.-L. (2012). Development of high-density genetic maps for barley and wheat using a novel two-enzyme genotyping-by-sequencing approach. PLoS ONE 7:e32253. doi: 10.1371/journal.pone.0032253

Pritchard, J. K., Stephens, M., Rosenberg, N. A., and Donnelly, P. (2000). Association mapping in structured populations. Am. J. Hum. Genet. 67, 170-181. doi: 10.1086/302959

Quarrie, S., Quarrie, S. P., Radosevic, R., Rancic, D., Kaminska, A., Barnes, J., et al. (2006). Dissecting a wheat QTL for yield present in a range of environments: from the QTL to candidate genes. J. Exp. Bot. 57, 2627-2637. doi: $10.1093 /$ jxb/erl026

Quraishi, U. M., Murat, F., Abrouk, M., Pont, C., Confolent, C., Oury, F. X., et al. (2011). Combined meta-genomics analyses unravel candidate genes for the grain dietary fiber content in bread wheat (Triticum aestivum L.). Funct. Integr. Genomics 11, 71-83. doi: 10.1007/s10142-010-0183-2

Rasheed, A., Xia, X. C., Mahmood, T., Quraishi, U. M., Bux, H., Napar, A. A., et al. (2015). Comparison of economically important loci in landraces and historical wheat cultivars from Pakistan. Crop Sci. doi: 10.2135/cropsci2015.01.0015

Ray, D. K., Mueller, N. D., West, P. C., and Foley, J. A. (2013). Yield trends are insufficient to double global crop production by 2050. PLOS ONE 8:e66428. doi: 10.1371/journal.pone.0066428

Ray, D. K., Ramankutty, N., Mueller, N. D., West, P. C., and Foley, J. A. (2012). Recent patterns of crop yield growth and stagnation. Nat. Commun. 3, 1293. doi: $10.1038 /$ ncomms 2296

Richards, R. A., Hunt, J. R., Kirkegaard, J. A., and Passioura, J. B. (2014). Yield improvement and adaptation of wheat to water-limited environments in Australia-a case study. Crop Pasture Sci. 65, 676-689. doi: 10.1071/CP13426

Saintenac, C., Jiang, D., and Akhunov, E. (2011). Targeted analysis of nucleotide and copy number variation by exon capture in allotetraploid wheat genome. Genome Biol. 12:R88. doi: 10.1186/gb-2011-12-9-r88

Sakamoto, T., Miura, K., Itoh, H., Tatsumi, T., Ueguchi-Tanaka, M., Ishiyama, K., et al. (2004). An overview of gibberellin metabolism enzyme genes and their related mutants in rice. Plant Physiol. 134, 1642-1653. doi: 10.1104/pp.103.033696

Salekdeh, G. H., Reynolds, M., Bennett, J., and Boyer, J. (2009). Conceptual framework for drought phenotyping during molecular breeding. Trends Plant Sci. 14, 488-496. doi: 10.1016/j.tplants.2009.07.007

Salse, J., Abrouk, M., Murat, F., Quraishi, U., and Feuillet, C. (2009). Improved criteria and comparative genomics tool provide new insights into grass paleogenomics. Brief. Bioinformatics 10, 619-630. doi: 10.1093/bib/ bbp037

Salse, J., Bolot, S., Throude, M., Jouffe, V., Piegu, B., Quraishi, U. M., et al. (2008). Identification and characterization of shared duplications between rice and wheat provide new insight into grass genome evolution. Plant Cell 20, 11-24. doi: $10.1105 /$ tpc. 107.056309 
Sayre, K. D., Rajaram, S., and Fischer, R. A. (1997). Yield potential progress in short bread wheats in northwest Mexico. Crop Sci. 37, 36-42. doi: 10.2135/cropsci1997.0011183X003700010006x

Storey, J. D., and Tibshirani, R. (2003). Statistical significance for genomewide experiments. Proc. Natl. Acad. Sci. U.S.A. 100, 9440-9445. doi: 10.1073/pnas.1530509100

Sukumaran, S., Dreisigacker, S., Lopes, M., Chavez, P., and Reynolds, M. P. (2015). Genome-wide association study for grain yield and related traits in an elite spring wheat population grown in temperate irrigated environments. Theor. Appl. Genet. 128, 353-363. doi: 10.1007/s00122-014-2435-3

Sukumaran, S., and Yu, J. (2014). "Association mapping of genetic resources: achievements and future perspectives," in Genomics of Plant Genetic Resources, eds R. Tubersoa, A. Garner, and E. Frison (Springer), 207-235.

Sun, X. Y., Wu, K., Zhao, Y., Kong, F. M., Han, G. Z., Jiang, H. M., et al. (2009). QTL analysis of kernel shape and weight using recombinant inbred lines in wheat. Euphytica 165, 615-624. doi: 10.1007/s10681-008-9794-2

Tahir, R., Kazi, A. G., Rasheed, A., Napar, A. A., Ajmal, S. U., and MujeebKazi, A. (2014). Evaluation of Pakistani elite wheat germplasm for T1BL.1RS chromosome translocation. J. Agric. Sci. Technol. 16, 421-423.

The International Wheat Genome Sequencing Consortium (IWGSC). (2014). A chromosome-based draft sequence of the hexaploid bread wheat (Triticum aestivum) genome. Science 345, 6194. doi: 10.1126/science. 1251788

Valluru, R., Reynolds, M., and Salse, J. (2014). Genetic and molecular bases of yield-associated traits: a translational biology approach between rice and wheat. Theor. Appl. Genet. 127, 1463-1489. doi: 10.1007/s00122-014-2332-9

Wang, J., Liu, W., Wang, H., Li, L., Wu, J., Yang, X., et al. (2011). QTL mapping of yield-related traits in the wheat germplasm 3228. Euphytica 177, 277-292. doi: 10.1007/s10681-010-0267-z

Wang, J. R., Luo, M. C., Chen, Z. X., You, F. M., Wei, Y. M., Zheng, Y. L., et al. (2013). Aegilops tauschii single nucleotide polymorphisms shed light on the origins of wheat $\mathrm{D}$-genome genetic diversity and pinpoint the geographic origin of hexaploid wheat. New Phytol. 198, 925-937. doi: 10.1111/nph.12164

Wang, R. X., Hai, L., Zhang, X. Y., You, G. X., Yan, C. S., and Xiao, S. H. (2009). QTL mapping for grain filling rate and yield-related traits in RILs of the Chinese winter wheat population Heshangmai x Yu8679. Theor. Appl. Genet. 118, 313-325. doi: 10.1007/s00122-008-0901-5

Wang, S. C., Wong, D. B., Forrest, K., Allen, A., Chao, S. M., Huang, B. E., et al. (2014). Characterization of polyploid wheat genomic diversity using a high-density 90000 single nucleotide polymorphism array. Plant Biotechnol. J. 12, 787-796. doi: 10.1111/pbi.12183

Wang, X., Jing, Y., Zhang, B., Zhou, Y., and Lin, R. (2015). Glycosyltransferaselike protein ABI8/ELD1/KOB1 promotes Arabidopsis hypocotyl elongation through regulating cellulose biosynthesis. Plant Cell Environ. 38, 411-422. doi: $10.1111 /$ pce. 12395

Yu, J., and Buckler, E. S. (2006). Genetic association mapping and genome organization of maize. Curr. Opin. Biotechnol. 17, 155-160. doi: 10.1016/j.copbio.2006.02.003

Yu, Y., Guo, G., Lv, D., Hu, Y., Li, J., Li, X., et al. (2014). Transcriptome analysis during seed germination of elite Chinese bread wheat cultivar Jimai 20. BMC Plant Biol. 14:20. doi: 10.1186/1471-2229-14-20

Zanke, C. D., Ling, J., Plieske, J., Kollers, S., Ebmeyer, E., Korzun, V., et al. (2014b). Whole genome association mapping of plant height in winter wheat (Triticum aestivum L.). PLOS ONE 9:e113287. doi: 10.1371/journal.pone. 0113287

Zanke, C., Ling, J., Plieske, J., Kollers, S., Ebmeyer, E., Korzun, V., et al. (2014a). Genetic architecture of main effect QTL for heading date in European winter wheat. Front. Plant Sci. 5:217. doi: 10.3389/fpls.2014.00217

Zhang, H., Mao, X., Wang, C., and Jing, R. (2010a). Overexpression of a common wheat gene TaSnRK2.8 enhances tolerance to drought, salt and low temperature in Arabidopsis. PLoS ONE 5:e16041. doi: 10.1371/journal.pone.0016041

Zhang, L. Y., Liu, D. C., Guo, X. L., Yang, W. L., Sun, J. Z., Wang, D. W., et al. (2010b). Genomic distribution of quantitative trait loci for yield and yield-related traits in common wheat. J. Integr. Plant Biol. 52, 996-1007. doi: 10.1111/j.1744-7909.2010.00967.x

Conflict of Interest Statement: The authors declare that the research was conducted in the absence of any commercial or financial relationships that could be construed as a potential conflict of interest.

Copyright (C) 2015 Ain, Rasheed, Anwar, Mahmood, Imtiaz, Mahmood, Xia, He and Quraishi. This is an open-access article distributed under the terms of the Creative Commons Attribution License (CC BY). The use, distribution or reproduction in other forums is permitted, provided the original author(s) or licensor are credited and that the original publication in this journal is cited, in accordance with accepted academic practice. No use, distribution or reproduction is permitted which does not comply with these terms. 